An arbitrary index of the viscous resistance involved in ventilation has been devised from measurements of the difference in distensibility of the lungs at different respiration rates.

The index of viscous resistance measured in 20 normal human lungs increased with the age of the patient.

Comparison of the index of viscous resistance on air with that on hydrogen shows that the increase in viscous resistance demonstrated in normal lungs is not primarily due to bronchial obstruction.

It is suggested that what has in the past been termed "loss of pulmonary elasticity" may represent a relative loss of elasticity due to an increase in the viscous element of the visco-elastic response of the lungs.

REFERENCES

Bayliss, L. E., and Robertson, G. W. (1939). Quart. J. exp. Physiol., $29,27$.

Dean, R. B., and Visscher, M. B. (1941). Amer. J. Physiol., 134, 450 McIlroy, M. B. (1952). Thorax, 7, 285.

\title{
A POST-MORTEM STUDY OF THE VISCO-ELASTIC PROPERTIES OF THE LUNGS IN EMPHYSEMA
}

\author{
BY \\ M. B. McILROY AND R. V. CHRISTIE \\ From the Medical Professorial Unit, St. Bartholomew's Hospital, London
}

(RECEIVED FOR PUBLICATION OCTOBER 6, 1952)

It has been shown in the previous paper that the visco-elastic response of isolated lungs to ventilation can be studied in a plethysmograph. In this paper the behaviour of lungs from patients with emphysema has been studied in the plethysmograph in the same way.

\section{Methods}

The lungs were removed at necropsy as already described, and after inflation to open up collapsed alveoli and restore the lung volume to about that found during life, the lungs were ventilated in the plethysmograph by means of a hand pump. The arbitrary index of viscous resistance was measured in each case by comparing the response of the lungs to ventilation at 3 and 15 respirations per minute. In some cases the lungs were ventilated with hydrogen as well as air to assess the degree of bronchial obstruction.

The lung volume and mixing efficiency were measured before and after death in a number of patients. At the end of each experiment the lungs were fixed by pouring formalin down the trachea and examined macroscopically to assess the amount of debris in the bronchial tree. Large sections of the lungs were prepared by the technique of Gough, James, and Wentworth (1949) and representative areas of each lung were also examined microscopically.

\section{RESUlts}

Ten patients with emphysema were investigated between four and a half and 96 hours after death and clinical details of the cases are given in an appendix. Results are shown in Table I. The elastic recoil of the lungs as measured by the pressure generated in the obstructed trachea on opening the thorax varied between 0 and $3.2 \mathrm{~cm}$. $\mathrm{H}_{2} \mathrm{O}$ with a mean of $1.75 \mathrm{~cm} . \mathrm{H}_{2} \mathrm{O}$. These figures are smaller than those found in normal lungs ( 2.8 to $6.2 \mathrm{~cm}$. $\mathrm{H}_{2} \mathrm{O}$, mean $4.3 \mathrm{~cm} . \mathrm{H}_{2} \mathrm{O}$ ).

The lung volume and mixing efficiency were measured before and after death in six cases and in general there was moderately good agreement between ante-mortem and post-mortem measurements. The mixing efficiency during life was reduced in all cases and the figures after death were similarly reduced (Table I).

The "index of viscous resistance" was markedly increased in all patients, the range of values being 3.12 to 5.55 compared with the normal range of 1.18 to 2.18. This increase was found both at the arbitrary plethysmograph pressure of $-4 \mathrm{~cm}$. $\mathrm{H}_{2} \mathrm{O}$ and at the corrected level for each case. A typical tracing of the ventilation of emphysematous lungs at 3 and 15 respirations per minute is shown in Fig. 1. This shows that in emphysema the lungs respond to a constant pressure swing with a constant tidal air in the same way as normal lungs, and also illustrates the marked reduction in tidal air with more rapid breathing.

The results of experiments with hydrogen in four cases are shown in Table II. In each case 
TABLE I

OBSERVATIONS ON TEN PATIENTS WITH EMPHYSEMA

\begin{tabular}{|c|c|c|c|c|c|c|c|c|c|}
\hline \multirow{2}{*}{$\begin{array}{l}\text { Time } \\
\text { after } \\
\text { Death } \\
\text { (hours) }\end{array}$} & \multirow{2}{*}{$\begin{array}{c}\text { Age } \\
\text { (years) }\end{array}$} & \multirow{2}{*}{$\begin{array}{c}\text { Intra- } \\
\text { tracheal } \\
\text { Pressure } \\
\left(\mathrm{cm} . \mathrm{H}_{2} \mathrm{O}\right)\end{array}$} & \multirow{2}{*}{$\begin{array}{l}\text { Lung Volume } \\
\text { after Infla- } \\
\text { tion in } \\
\text { Plethysmo- } \\
\text { graph (ml.) }\end{array}$} & \multirow{2}{*}{$\begin{array}{l}\text { Ante- } \\
\text { mortem } \\
\text { F.R.A. } \\
\text { (ml.) }\end{array}$} & \multirow{2}{*}{$\begin{array}{c}\text { Mixing } \\
\text { Efficiency } \\
\text { after } \\
\text { Death }\end{array}$} & \multirow{2}{*}{$\begin{array}{c}\text { Mixing } \\
\text { Efficiency } \\
\text { during } \\
\text { Life }\end{array}$} & \multicolumn{2}{|c|}{$\begin{array}{l}\text { Index of Viscous } \\
\text { Resistance at }\end{array}$} & \multirow{2}{*}{ Diagnosis } \\
\hline & & & & & & & $\begin{array}{l}\text { Corrected } \\
\text { Level }\end{array}$ & $\begin{array}{l}-4 \mathrm{~cm} \\
\mathrm{H}_{2} \mathrm{O}\end{array}$ & \\
\hline $4 !$ & 75 & $2 \cdot 7$ & 2,820 & 2,663 & $19 \cdot 2$ & 25 & $5 \cdot 0$ & $5 \cdot 0$ & $\begin{array}{l}\text { Emphysema: carcinoma of } \\
\text { bile duct }\end{array}$ \\
\hline 10 & 68 & 0 & 2,100 & 3,380 & $15 \cdot 5$ & 20 & $3 \cdot 7$ & $3 \cdot 12$ & Emphysema; hypertension \\
\hline 14 & 62 & 0 & 5,535 & 5,665 & $27 \cdot 5$ & $23 \cdot 6$ & $4 \cdot 0$ & & Emphysema; cor pulmonale \\
\hline 19 & 65 & $2 \cdot 0$ & 6,067 & 5,146 & $24 \cdot 3$ & 22 & $3 \cdot 84$ & $3 \cdot 34$ & Emphysema \\
\hline 20 & 46 & $2 \cdot 3$ & 3,744 & 5,500 & $22 \cdot 5$ & $13 \cdot 4$ & $5 \cdot 55$ & $4 \cdot 17$ & Emphysema; cor pulmonale \\
\hline 21 & 49 & $0 \cdot 8$ & 4,310 & 4,961 & & $23 \cdot 4$ & $4 \cdot 75$ & & Emphysema \\
\hline 26 & 62 & $3 \cdot 2$ & & & & & $5 \cdot 0$ & $4 \cdot 75$ & $\begin{array}{l}\text { Emphysema; coronary throm- } \\
\text { bosis }\end{array}$ \\
\hline 28 & 62 & $2 \cdot 8$ & & & & & $3 \cdot 45$ & $3 \cdot 45$ & $\begin{array}{l}\text { Emphysema; auricular fibril } \\
\text { lation }\end{array}$ \\
\hline $\begin{array}{l}34 \\
96\end{array}$ & $\begin{array}{l}53 \\
52\end{array}$ & $2 \cdot 7$ & & & & & $4 \cdot 25$ & $4 \cdot 0$ & Emphysema \\
\hline 96 & 52 & $1 \cdot 0$ & 2,300 & & & & $5 \cdot 0$ & $4 \cdot 55$ & ," \\
\hline
\end{tabular}

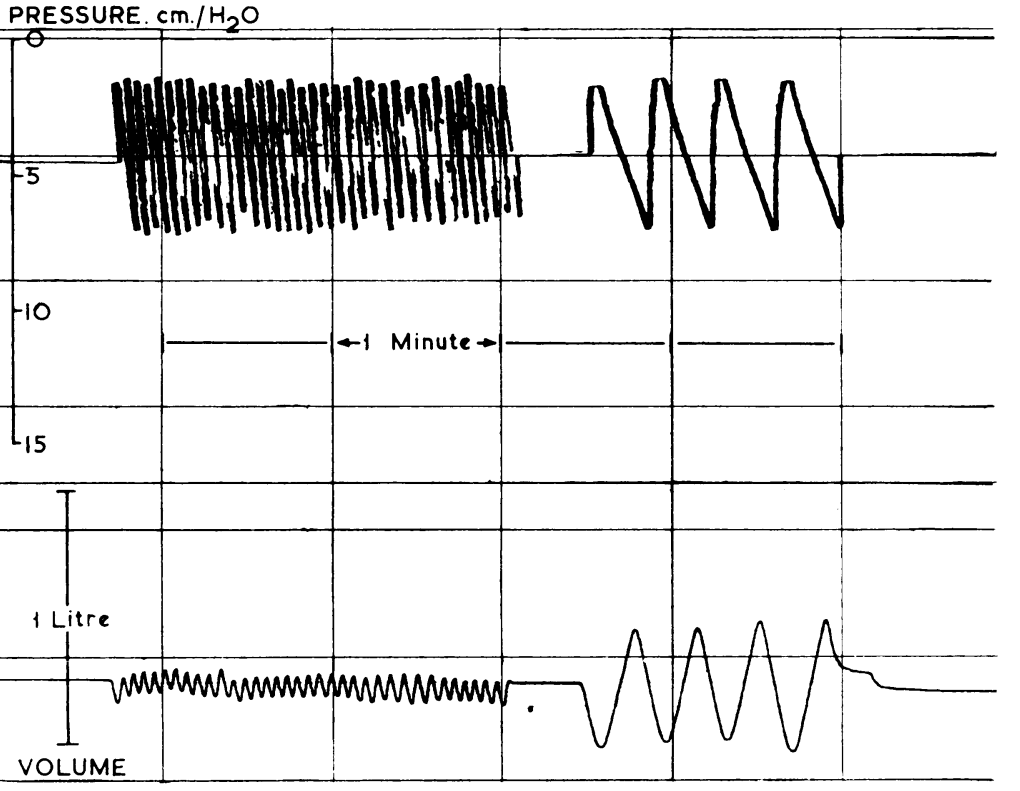

FIG. 1.-Ventilation at different respiratory rates of lungs from a patient with emphysema Upper tracing represents plethysmograph pressure and lower tracing vo'ume of air passing in and out of the lungs. With more rapid respiration the vo'ume of tida! air is greatly reduced (Compare Fig. 2 in previous paper.)

TABLE II

INDEX OF VISCOUS RESISTANCE IN LUNGS OF FOUR PATIENTS WITH EMPHYSEMA VENTILATED WITH AIR AND HYDROGEN

\begin{tabular}{|c|c|c|c|c|c|c|c|}
\hline \multirow{3}{*}{$\begin{array}{c}\text { Age } \\
\text { (years) }\end{array}$} & \multirow{3}{*}{$\begin{array}{l}\text { Hydrogen } \\
\text { Concen- } \\
\text { tration } \\
(\%)\end{array}$} & \multicolumn{3}{|c|}{$\begin{array}{l}\text { Index of Viscous Resis- } \\
\text { tance at Corrected Level }\end{array}$} & \multicolumn{3}{|c|}{$\begin{array}{l}\text { Index of Viscous Resis- } \\
\text { tance at }-4 \mathrm{~cm} . \mathrm{H}_{2} \mathrm{O}\end{array}$} \\
\hline & & \multirow{2}{*}{ Air } & \multicolumn{2}{|c|}{ Hydrogen } & \multirow{2}{*}{ Air } & \multicolumn{2}{|c|}{ Hydrogen } \\
\hline & & & Predicted & Observed & & Predicted & Observed \\
\hline $\begin{array}{l}46 \\
49 \\
62 \\
65\end{array}$ & $\begin{array}{l}85 \\
85 \\
90 \\
88\end{array}$ & $\begin{array}{l}5.55 \\
4.75 \\
5.0 \\
3.5\end{array}$ & $\begin{array}{l}3 \cdot 64 \\
3 \cdot 18 \\
3 \cdot 18 \\
2 \cdot 47\end{array}$ & $\begin{array}{l}5 \cdot 0 \\
3 \cdot 44 \\
4 \cdot 0 \\
2 \cdot 99\end{array}$ & $\begin{array}{l}4 \cdot 15 \\
4 \cdot 75\end{array}$ & $\begin{array}{l}2 \cdot 86 \\
3 \cdot 1\end{array}$ & $\begin{array}{l}4 \cdot 35 \\
4 \cdot 0\end{array}$ \\
\hline
\end{tabular}

the observed index of viscous@ resistance with hydrogen was greater than the predicted $\stackrel{\Phi}{工}$ value (McIlroy and Christie, $\vec{\oplus}$ p. 291). In other words, the N observed reduction in the index of viscous resistanceo with hydrogen was less than would have been expected if $\bar{D}$ all the viscous resistance had $\frac{\mathrm{Q}}{D}$ been produced in the air $\varrho$ passages. It follows that there $\overrightarrow{\overrightarrow{0}}$ is a tissue viscous resistance 3 in emphysema which is independent of the viscosity of the gas breathed.

\section{Discussion}

The principal difference $\frac{\sigma}{3}$ observed between normal and emphysematous lungs is in the speed of response to a change

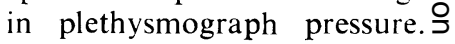
Both normal and emphy- $\frac{D}{0}$ sematous lungs have been found to respond to a con- N stant pressure swing with a constant tidal air, but in emphysema the response $\mathcal{N}$ depends largely on the respiratory rate. The index $\omega$ of viscous resistance is, therefore, much greater than that found in normal lungs. From the experiments with hydrogen it is clear that this increase $\mathbb{D}$ of viscous resistance in emphysema is due prin $\stackrel{?}{?}$ cipally to an increase in tissue viscous resistance $\frac{T}{0}$ and not to bronchial obstruction.

From a comparison of the ante-mortem and $\stackrel{\mathbb{P}}{\mathbb{P}}$ post-mortem lung volumes it is clear that the post- $\unrhd$ mortem experiments were carried out with the lungs inflated to a volume comparable with that 0 
in life. The discrepancy between the values obtained before and after death in two of the cases may have been due to consolidation of the lower lobes occurring shortly before death.

The significance of these results must be viewed in the light of previous work on the loss of pulmonary elasticity in emphysema. It has been suggested in a previous paper (McIlroy and Christie, p. 291) that the distensibility of the lungs calculated from the intrapleural pressure swing and tidal air is an index of visco-elastic response and not, as has previously been thought, of true elasticity. The elastic element of the response of the lungs can only be measured in static experiments in which time is allowed for equilibrium to be reached. It has been shown by Christie (1934) that in emphysema this elastic element may be absent. He found that in a patient with emphysema the intrapleural pressure reverted to atmospheric when the patient held his breath at the end of inspiration. It has been found impossible to carry out repeatable static experiments with emphysematous lungs after death, and the only evidence concerning the elastic recoil has been obtained from measurements of intratracheal pressure on opening the thorax with the lungs in situ. The findings in 10 cases confirm that in emphysema the elastic recoil of the lungs is reduced, but in only two patients was elastic recoil completely absent.

From the experiments with normal lungs it has been suggested (McIlroy and Christie, p. 291) that an increase in the index of viscous resistance may be considered to indicate a relative decrease in the elastic element of the visco-elastic response of the lungs. The results in patients with emphysema confirm this suggestion and support the view that what has been called "loss of elasticity" in the past is largely an increase in tissue viscous resistance. That there is also an absolute reduction in the elastic element in emphysema cannot be disputed, and this may well be responsible for the increase in lung volume up to the limit of the size of the thorax. Confirmation of this hypothesis on the nature of loss of elasticity may be found by reconsidering the results reported in a previous paper (Christie, 1934), in which it was shown that in emphysema the distensibility of the lungs was greater when measured from vital capacity tracings than from the resting tidal air and intrapleural pressure. The maximum inspirations were made slowly at a rate of approximately five respirations per minute as compared with the $15-20$ per minute of the patient's normal breathing, and in fact these results show that during life the distensibility of the lungs in emphysema depends largely on the respiratory rate. These findings suggest that our conclusions, though based on results obtained under artificial conditions with the lungs hanging unsupported in a plethysmograph, may nevertheless be applicable to the behaviour of the lungs during life.

It is possible to explain some of the disturbances in pulmonary function in emphysema on the basis of an increase in viscous resistance. Reduction in maximal breathing capacity may in part be due to the patient's inability to increase the rate and depth of breathing without greatly increasing the work done against viscous resistance. Similarly the reduction in tidal air on hyperventilation sometimes seen in patients with emphysema may be due to an increase in viscous resistance with more rapid breathing.

From our results it is also possible that the amount of work done in ventilation may be raised even with quiet breathing, for the high viscous resistance encountered more than balances any decrease in elastic resistance. This increase in work may well be a factor in the production of dyspnoea. It must be stressed that increased viscous resistance during life shows up not as a delay in the response of the lungs but as an increase in the pressure swing necessary to produce a given change in volume in a given time. It is, however, feasible that the tendency of the lungs to lag behind the change in intrapleural pressure may increase the strain on the surface of the lung and be a factor in the production of bullae.

\section{SUMmary}

The visco-elastic properties of the lungs of 10 patients with emphysema have been studied on ventilation in a plethysmograph after death.

The values for lung volume and mixing efficiency measured after death are of the same order as those obtained during life.

The viscous resistance to ventilation is increased in emphysematous lungs.

It is shown by experiments using hydrogen that the increase in viscous resistance in emphysema is due principally to changes in the lungs and not to bronchial obstruction.

The significance of these conclusions in relation to impairment of pulmonary function in emphysema is discussed.

\section{REFERENCES}

Christie, R. V. (1934). J. clin. Invest., 13, 295

Gough, J., James, W. R. L., and Wentworth, J. E. (1949). J. Facult

Radiol. (Lond.). 1, 28.
McIlroy, M. B., and Christie, R. V. (1952). Thorax, 7, 291. 


\section{A P P E N D I X \\ CASE RePorts}

CASE 1.-W. D., aged 75. Retired.

Winter cough and dyspnoea for many years. Six months abdominal pain and jaundice.

On examination, jaundice; barrel chest; liver enlarged.

Necropsy, heart 245 g. ; lungs, emphysema ; carcinoma of head of pancreas; secondary deposits in liver.

CASe 2.-A. P., aged 65. Newsvendor.

Twelve years cough, worse in winter. Four years dyspnoea. One year oedema of ankles.

Cyanosis; heart not clinically enlarged, B.P. 150/ 100 ; scattered rhonchi and sibilli; liver enlarged; ascites; gross oedema of legs and trunk.

Necropsy, heart 720 g., hypertrophy of right and left ventricles; lungs, emphysema.

CASE 3.-F. F., aged 62. Warehouseman.

Winter cough for many years. One year severe dyspnoea. On examination, cyanosis, polycythaemia, clubbing of fingers. B.P. $160 / 88$; barrel-shaped chest ; scattered rhonchi. Patient died in coma.

Necropsy, heart 475 g., hypertrophy of right and left ventricles; lungs, emphysema, congestion, and bronchopneumonia.

CASE 4.-A. W., aged 65. French polisher.

Fifty years cough. Four years dyspnoea.

Kyphoscoliosis ; barrel-shaped chest ; B.P. 115/80 ; scattered rhonchi; liver enlarged.

Died in coma.

Necropsy, heart 320 g., hypertrophy of right ventricle; gross emphysema with a small area of bronchopneumonia at right base.

CASE 5.-G. R., aged 46. Lorry driver.

Fifteen years bronchitis. Four years dyspnoea. Three years recurrent attacks of heart failure responding to treatment.
Cyanosis; exophthalmos; barrel-shaped chest scattered rhonchi; clubbing of fingers; liver enc larged; oedema of hands and legs.

Necropsy, heart $555 \mathrm{~g}$., right ventricular hyperत्त trophy; lungs, gross emphysema with broncho pneumonia at both bases.

CASE 6.-C. N., aged 49. Decorator.

Nine years winter cough. Five years dyspnoea.

On examination, cyanosis; B.P. 154/100; barrel $\vec{\omega}$ shaped chest; scattered rhonchi; liver enlarged.

Necropsy, heart 420 g., right ventricular hyper trophy ; lungs, emphysema.

CASE 7.--G. P., aged 62. Scaffolder.

Winter cough for many years. Three years dys $\mathcal{G}$ pnoea. Six months oedema of ankles.

Cyanosis; orthopnoea; auricular fibrillation, B.P? 115/80 ; barrel-shaped chest; scattered rhonchi liver enlarged; oedema of legs and back.

Necropsy, heart 615 g.; right ventricular hyper trophy; ischaemic scarring of heart muscle; ante mortem thrombus in right auricular appendix ; lungs@ emphysema.

CASE 8.-W.C., aged 62. Gas foreman.

Brought in dead.

Necropsy, heart 380 g.; right ventricular hyper trophy; myocardial fibrosis; coronary atheroma emphysema of lungs.

CASE 9.-A. H., aged 53. Dental mechanic.

Twenty-five years winter cough. Seven years̊ dyspnoea.

Cyanosis ; B.P., 118/80 ; barrel-shaped chest ; scattered rhonchi; liver enlarged.

Necropsy, heart $360 \mathrm{~g}$.; right ventricular hyper trophy; lungs, emphysema; gastric ulcer.

CASE 10.--D. O., aged 52. Collier.

One year underground. Two years dyspnoea.

Necropsy, right ventricular hypertrophy; lungs: emphysema; chronic gastric ulcer. 